\title{
Rapid and Accurate Simultaneous Determination of Abamectin and Ivermectin in Bovine Milk by High Performance Liquid Chromatography with Fluorescence Detection
}

\author{
D. I. S. Kolberg, M. A. Presta, C. Wickert, M. B. Adaime and R. Zanella* \\ Laboratório de Análises de Resíduos de Pesticidas, Departamento de Química, \\ Universidade Federal de Santa Maria, 97105-900 Santa Maria-RS, Brazil
}

\begin{abstract}
Um método analítico empregando cromatografia líquida de alta eficiência com detecção por fluorescência para a determinação simultânea de abamectin e ivermectin em leite bovino foi desenvolvido e validado. Os melhores resultados de recuperação foram obtidos empregando acetonitrila na extração dos compostos, com purificação do extrato por extração em fase sólida em cartuchos contendo $\mathrm{C}_{18}$. A derivação pré-coluna foi realizada com $N$-metilimidazol e anidrido trifluoracético. Os limites de detecção (LOD) do método para abamectin e ivermectin foram 0,10 e $0,14 \mu \mathrm{g} \mathrm{L} \mathrm{L}^{-1}$ e os limites de quantificação (LOQ) foram 0,18 e $0,36 \mu \mathrm{g} \mathrm{\textrm {L } ^ { - 1 }}$, respectivamente. As recuperações foram de 75 a $101 \%$, com valores de RSD abaixo de $10 \%$. Os valores de LOD e LOQ obtidos são inferiores aos limites máximos de resíduos em leite estabelecidos pelo Codex Alimentarius, União Européia e legislação brasileira.
\end{abstract}

An analytical method using high performance liquid chromatography with fluorescence detection for the simultaneous determination of abamectin and ivermectin in bovine milk was developed and validated. The best recovery results were achieved by using acetonitrile for extraction of the compounds followed by solid phase extraction in cartridges containing $\mathrm{C}_{18}$ for the purification of the extract. Pre-column derivatization was accomplished with $\mathrm{N}$-methylimidazole and trifluoroacetic anhydride. The method limit of detection (LOD) values for abamectin and ivermectin were 0.10 and $0.14 \mu \mathrm{g} \mathrm{L}^{-1}$ and the limit of quantification (LOQ) values were 0.18 and $0.36 \mu \mathrm{g} \mathrm{L}^{-1}$, respectively. The recoveries were from 75 to $101 \%$, with RSD values lower than $10 \%$. The LOD and LOQ values are lower than the maximum residue limits (MRLs) in milk established by Codex Alimentarius, European Union and the Brazilian legislation.

Keywords: veterinary drugs, milk, liquid chromatography, fluorescence detection, derivatization

\section{Introduction}

The occurrence of drug residues in food and foodstuffs originating from veterinary treatments has become increasingly noticeable. Milk is known as a nutritious wholesome food consumed globally and it is an inexpensive source of protein and calcium essential for promoting growth in children and the general good health of population. ${ }^{1}$

Industrial development has led to the discovery of new chemical groups, including avermectins. Avermectins, a family of pesticide agents, are a product of the fermentation process with the microorganism Streptomyces avermetilis, and caused significant changes in the control of helminths

*e-mail: rzanella@base.ufsm.br and ectoparasitis in animals. ${ }^{2,3}$ The compounds abamectin and ivermectin, shown in Figure 1, are macrocyclic lactones. Abamectin, a precursor to ivermectin, differs from ivermectin in that it has a double-bond at the $\mathrm{C}_{22-23}$ position. It is used throughout the world to treat parasitic helminths and insect pests in man and animals. ${ }^{4}$ Abamectin is constituted of a mixture of two homologues, having $80 \%$ of avermectin $\mathrm{B}_{1 \mathrm{a}}$ and not more than $20 \%$ of avermectin $\mathrm{B}_{1 \mathrm{~b}}{ }^{3}$ Abamectin was developed as an insecticide and acaricide for contact and stomach action and is highly effective against gastrointestinal nematodes of cattle, ${ }^{4,5}$ but is not approved for use in dairy animals. ${ }^{6}$

Ivermectin is derived from abamectin and consists of a mixture of two homologues: 5-O-dimethyl-22,23dihydroavermectin $\mathrm{B}_{1 \mathrm{a}}$ and $\mathrm{B}_{1 \mathrm{~b}}$ in a ratio of $80: 20 .^{7}$ Ivermectin is widely used as an antihelmintic in veterinary 


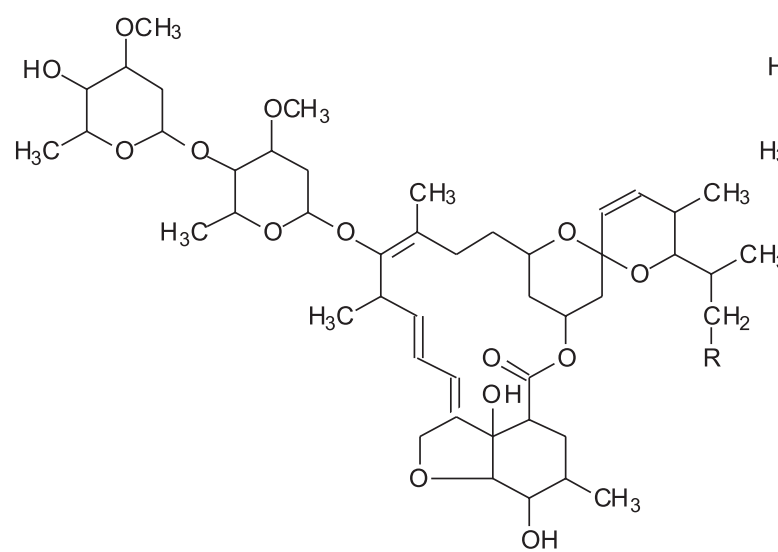

Abamectin

Figure 1. Structure of abamectin and ivermectin.

medicine and is used to treat onchocerciasis or river blindness in humans, ${ }^{6,8}$ but as well as for abamectin it is not approved for use in dairy animals. ${ }^{6,9}$

The monitoring of veterinary drugs residues is very important for controlling the safety of milk for human consumption. ${ }^{1}$ Avermectins are highly lipophilic and are stored in fat tissue, which acts as a reservoir, contributing to their long-term persistence in the body. ${ }^{10} \mathrm{~A}$ large number of pharmacokinetic studies are available for these compounds, reporting a large volume of distribution, long residence time and extensive elimination in milk during lactation, where it is possible to find residues of these compounds in milk after analysis. ${ }^{8}$

Milk contaminated by residues of veterinary drugs in concentrations above the maximum residue limit (MRL) is considered adulteration and inappropriate for consumption, representing risks to public health, technological and commercial risks to the dairy industry.

For milk, the Brazilian legislation has established a MRL of $1 \mu \mathrm{g} \mathrm{kg}^{-1}$ for abamectin ${ }^{11}$ and $10 \mu \mathrm{g} \mathrm{kg}^{-1}$ for ivermectin. ${ }^{12}$ The Codex Alimentarius recommends a MRL of $5 \mu \mathrm{g} \mathrm{kg}^{-1}$ for abamectin ${ }^{13}$ and $10 \mu \mathrm{g} \mathrm{L} \mathrm{L}^{-1}$ for ivermectin. ${ }^{14}$ In the European Union the use of abamectin in cattle producing milk for human consumption is forbidden, whereas for ivermectin no MRL is established for milk. ${ }^{6,15-17}$

The determination of veterinary drugs in milk presents some problems because the most common approaches involve total extraction of fat by liquid-liquid extraction. The main drawbacks of this procedure are: the demanded amount of solvents and glassware, the number of step manual operations involved and the necessity of centrifugation after each extraction. ${ }^{18}$

Detection of misuse or inadvertent contamination in milk requires a sensitive analytical method. Liquid chromatography with fluorescence detection is an attractive choice for the determination of antibiotics due to its higher selectivity, sensitivity and precision. ${ }^{1}$ Although a number of liquid chromatography-tandem mass spectrometry (LCMS/MS) methods have been described for the analysis of avermectins, ${ }^{8,16,18-21}$ fluorescence detection is still the most commonly applied detection technique and presents similar limits of detection and quantification, with advantages in terms of equipment costs. ${ }^{5,7,9,10,17,22-26}$

The use of fluorescence detection requires an efficient derivatization to generate a fluorogenic moiety within the molecule. ${ }^{17}$ Fluorescent derivatives of avermectins can be formed by: $i$ ) reacting them with acetic anhydride at $95^{\circ} \mathrm{C}$ for $1 \mathrm{~h}$ in the presence of $\mathrm{N}$-methylimidazole, ${ }^{6,22-25}$ but this derivatization reaction results in many reagent by-products, thus further cleanup of the derivatized standards and sample is required; $i$ ) when trifluoroacetic anhydride is substituted by acetic anhydride, the derivatization of avermectins takes place in less than $30 \mathrm{~s}$ at $25{ }^{\circ} \mathrm{C} .5,9,10,26$ Because fewer reagent by-products are formed, an additional cleanup of the derivatized standards and samples is not required.

Diserens and Henzelin ${ }^{5}$ used trifluoroacetic anhydride and $N$-methylimidazole in acetonitrile for the derivatization of abamectin and its metabolite 8,9-Z-avermectin $\mathrm{B}_{1}$ in fruits and vegetables. Schenck and Lagman ${ }^{10}$ also used this derivatization step. The trifluoroacetic derivatives formed are highly hydrophobic. These authors verified that the derivatized compounds underwent $50 \%$ degradation in $3 \mathrm{~h}$ when exposed to light, although, when protected from light, degradation was not observed for up to $6 \mathrm{~h}$.

Chiou et al., ${ }^{7}$ Kijak, ${ }^{22}$ Schenck $^{23}$ and Dusi et al. ${ }^{24,25}$ used acetic anhydride and $\mathrm{N}$-methylimidazole in $\mathrm{N}, \mathrm{N}$ dimethylformamide for derivatization of abamectin. This derivatization reaction was slow, making a cleanup step of the derivatized compounds still necessary. 
The general disadvantages of the reported methods include: multiple extraction, liquid-liquid partition, more than one cleanup step and a long total analysis time. Therefore, a new method was proposed in this study to improve the speed of analysis by simplifying the extraction step, using less solvent and time to determine abamectin and ivermectin in bovine milk by HPLC with fluorescence detection.

\section{Experimental}

\section{Chemicals and materials}

Acetonitrile and tetrahydrofuran (THF), both LC grade, were purchased from J.T. Baker (USA); dimethyldichlorosilane and triethylamine $99 \%$ were obtained from Sigma-Aldrich (Germany); $N$-methylimidazole 99\% and trifluoroacetic anhydride $>99 \%$ were purchased from AcrosOrganics (USA). High purity water was obtained from a Milli-Q water system (Millipore, Bedford, MA, USA).

Reference standards of abamectin and ivermectin with 90 and $95 \%$ purity, respectively, were purchased from Dr. Ehrenstorfer (Augsburg, Germany).

SPE Stracta $\mathrm{C}_{18}$-E cartridges $(500 \mathrm{mg}, 3 \mathrm{~mL}, 55 \mu \mathrm{m}$, $70 \AA$ ) were purchased from Phenomenex (USA); SPE manifold system was from Varian (USA); ultrasonic bath Bransonic 12 (Germany); centrifuge Sigma 3-10 (Germany).

\section{Instrumental analysis}

For the HPLC analysis, the following equipment and conditions were used: LC-10AD pump from Shimadzu (Japan), operating at an isocratic flow rate of $0.8 \mathrm{~mL} \mathrm{~min}^{-1}$; 821-FP fluorescence detector form Jasco (Japan) operated at $364 \mathrm{~nm}$ for excitation and $475 \mathrm{~nm}$ for emission; Spherisorb $\mathrm{C}_{18}$ ODS-2 $(250 \times 4.6 \mathrm{~mm}$ i.d.; $5 \mu \mathrm{m})$ analytical column and $\mathrm{C}_{18}$ guard column $(20 \times 1 \mathrm{~mm})$ from Waters (USA). The volume of injection was $100 \mu \mathrm{L}$.

\section{Preparation of solutions and standards}

A mixture of acetonitrile:THF:water (90:6:4, v/v/v) was used as HPLC mobile phase. A fresh solution of the derivatization reagent was prepared daily using trifluoroacetic anhydride and acetonitrile $(1: 2, \mathrm{v} / \mathrm{v})$. The solution was stored in a brown-glass flask. All glassware was silanized with a solution of dimethyldichlorosilane $5 \%(\mathrm{v} / \mathrm{v})$ prepared in toluene. The SPE cartridges were conditioned using a mixture of acetonitrile:water:triethyla mine (30:70:0.2, v/v/v).
Stock solutions of the standards containing $1 \mathrm{mg} \mathrm{L}^{-1}$ of ivermectin and $100 \mathrm{mg} \mathrm{L}^{-1}$ of abamectin were prepared in acetonitrile and stored in brown-glass flasks at $-20^{\circ} \mathrm{C}$. Standard solutions containing $100 \mu \mathrm{g} \mathrm{L}^{-1}$ were prepared by dilution. These solutions were used to fortify the milk samples and to prepare the solutions used to generate the analytical calibration curves. Standards of abamectin were prepared by using $50,100,200,300,400$ and $500 \mu \mathrm{L}$ of the $100 \mu \mathrm{g} \mathrm{L}^{-1}$ solution, adding $2 \mathrm{~mL}$ of acetonitrile, $200 \mu \mathrm{L}$ $N$-methylimidazole and $600 \mu \mathrm{L}$ of derivatization reagent in silanized glass tubes. The tubes were closed, mixed briefly and stored in the dark. After 15 min the solution was diluted to $5 \mathrm{~mL}$ with acetonitrile, mixed and analyzed by HPLC. The concentrations were 1, 2, 4, 6, 8 and $10 \mu \mathrm{g} \mathrm{L} \mathrm{L}^{-1}$, respectively.

Working standards of ivermectin were prepared by using $100,200,400,600,800$ and $1000 \mu \mathrm{L}$ of the $100 \mu \mathrm{g} \mathrm{L}-1$ solution, and following the same steps carried out with abamectin. The resulting concentrations were 2, 4, 8, 12, 16 and $20 \mu \mathrm{g} \mathrm{L}^{-1}$, respectively. Since the derivatized solutions were not stable, freshly prepared working standards were prepared for each series of samples.

\section{Sample preparation}

The milk samples were raw bovine milk obtained from the Agro-ecological Dairy Farm of the Federal University of Santa Maria (UFSM). Aliquots of $10 \mathrm{~mL}$ of sample and $10 \mathrm{~mL}$ of acetonitrile were transferred to a $50 \mathrm{~mL}$ centrifuge tube and the mixture was manually shaken for $1 \mathrm{~min}$, followed by sonication for $10 \mathrm{~min}$ and finally was shaken once more for $1 \mathrm{~min}$. The sample was centrifuged for $5 \mathrm{~min}$ at $3600 \mathrm{rpm}$. Similar procedures were performed using other extraction solvents: ethanol, ethyl acetate, and isooctane $(10 \mathrm{~mL}$ of each) and $2.5 \mathrm{~mL}$ of ammonium hydroxide; $20 \mathrm{~mL}$ of ethanol:ethyl acetate $(5: 95, \mathrm{v} / \mathrm{v})$ and $30 \mathrm{~mL}$ ethyl acetate. The organic phase was transferred to a flask and $20 \mathrm{~mL}$ of deionized water and $30 \mu \mathrm{L}$ of triethylamine were added. After this, the concentration step was carried out using a $\mathrm{C}_{18}$ cartridge conditioned with $10 \mathrm{~mL}$ acetonitrile and $5 \mathrm{~mL}$ acetonitrile:water:triethylam ine (30:70:0.2, v/v/v). The compounds were eluted into silanized glass tubes with $20 \mathrm{~mL}$ of acetonitrile and the resulting extract evaporated under nitrogen flow at $60{ }^{\circ} \mathrm{C}$.

\section{Derivatization step}

The sample extract was reconstituted in $1 \mathrm{~mL}$ of acetonitrile and $200 \mu \mathrm{L} N$-methylimidazole and $600 \mu \mathrm{L}$ of derivatization reagent were added to the silanized glass tubes. The mixture was mixed briefly and stored in the 
dark. After $15 \mathrm{~min}, 100 \mu \mathrm{L}$ of this sample were injected into the HPLC system.

\section{Recovery study}

For the recovery studies, volumes of 18,90 and $180 \mu \mathrm{L}$ of a $100 \mu \mathrm{g} \mathrm{L}^{-1}$ solution of abamectin were used to fortify blank milk samples. The fortified samples had concentration levels equivalent to $0.18,0.9$ and $1.8 \mu \mathrm{g} \mathrm{L}^{-1}$ in milk corresponding to 1,5 and $10 \mu \mathrm{g} \mathrm{L} \mathrm{L}^{-1}$ in the final extract, respectively.

For ivermectin, volumes of 36,180 and $1800 \mu \mathrm{L}$ of a $100 \mu \mathrm{g} \mathrm{L}^{-1}$ solution of ivermectin were used in the fortification step, resulting in $0.36,1.8$ and $3.6 \mu \mathrm{g} \mathrm{L}^{-1}$ in milk and 2, 10 and $20 \mu \mathrm{g} \mathrm{L}^{-1}$ in the final, respectively. To obtain a homogeneous sample, the compounds were mixed with the milk matrix followed by 10 min sonication in an ultrasonic bath and then left to rest for $10 \mathrm{~min}$.

\section{Method validation}

The applicability of the developed method was tested following the accepted criteria for analytical method validation, considering sensibility, limit of detection, limit of quantification, linearity, precision and accuracy of the method.

The analytical calibration curves were obtained with external standards based on injections of the standard solutions prepared in acetonitrile and also in blank milk extract, because matrices may influence the analyte responses. Solutions with concentrations of 1, 2, 4, 6, 8 and $10 \mu \mathrm{g} \mathrm{L}^{-1}$ for abamectin and 2, 4, 8, 12, 16 and $20 \mu \mathrm{g} \mathrm{L}^{-1}$ for ivermectin were injected in triplicate. The average values were used to obtain the analytical calibration curves by plotting the corresponding peak area with analyte concentration.

In accordance with the recommendations of the International Conference on Harmonization (ICH) guidelines,${ }^{27}$ the instrument LOD and LOQ (LODi and LOQi, respectively) and the method LOD and LOQ (LODm and LOQm, respectively) were determined. The LODi was determined by analyzing standards solutions at a level that provided signals at three times above the background noises. LOQi values were identified at signal-to-noise ratios equal to 10 . The real LOQm was based on the accuracy and precision data, obtained via recovery determinations and was defined as the lowest validated spike level meeting the requirements of a recovery within the range of $70-120 \%$ and a RSD $\leq 20 \%$.

The method precision was expressed as repeatability (RSD), by analyzing a fortified sample three times at three different concentration levels on the same day and as intermediate precision (RSD), determined by repeating the study on three consecutive days. The method accuracy was determined by mean of percentage recoveries from fortified milk samples at three different concentration levels. ${ }^{28,29}$

\section{Results and Discussion}

\section{Sample preparation}

Several tests were carried out using different procedures reported in the literature. Extraction with several solvents and with liquid-liquid purification was not efficient to remove all the fat, required a large amount of solvent and was time consuming. Extraction with ethyl acetate ${ }^{30}$ showed poor separation of the phases and, even after centrifugation, resulted in many particles in the extract. Methods using liquid-liquid extraction with ethyl acetate, isooctane and ethanol ${ }^{10,22}$ were tested and shown to be more efficient when an additional SPE clean up with $\mathrm{C}_{18}$ cartridges was employed. The recoveries were satisfactory, considering the large number of involved steps, but the total time to prepare 4 samples was around $5 \mathrm{~h}$.

The proposed method showed that it is possible to achieve a good extraction of abamectin and ivermectin using only acetonitrile, because of the solubility of the compounds in this solvent, as well as its good deproteinizing effect. A small amount of triethylamine was added to the extract to reduce adsorption of the analytes on residual silanol groups of the SPE cartridge material.

This method had a shorter extraction time, used smaller volumes of solvents and resulted in a clean extract at the end of the derivatization step. After extraction and derivatization, abamectin and ivermectin presented good chromatographic resolution, as seen at the chromatogram of a spiked sample showed in Figure 2.

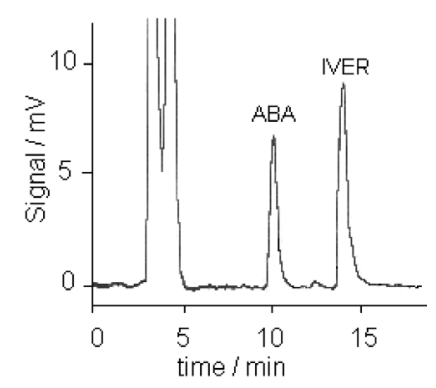

Figure 2. Chromatogram of the derivatives of a spiked sample containing abamectin $\left(0.7 \mu \mathrm{g} \mathrm{L}^{-1}, \mathrm{t}_{\mathrm{R}} 10.1 \mathrm{~min}\right)$ and ivermectin $\left(1.4 \mu \mathrm{g} \mathrm{L}-1, \mathrm{t}_{\mathrm{R}} 14.3 \mathrm{~min}\right)$.

\section{Evaluation of the derivatization reaction}

According to the literature, ${ }^{5,10}$ the derivatized analytes undergo degradation due to the effects of both light and 
temperature. For this reason, the stability of the derivatized samples was evaluated in the presence and absence of room lighting at different temperatures. For the first study, standard solutions containing $4 \mu \mathrm{g} \mathrm{L} \mathrm{L}^{-1}$ of abamectin and $8 \mu \mathrm{g} \mathrm{L}^{-1}$ of ivermectin were derivatized and then placed in two flasks, one transparent and the other protected from light. As shown in Figure 3, solutions of abamectin that were exposed to light showed $92 \%$ of degradation in $5 \mathrm{~h}$ of exposure to light. When the protected flasks were used, the compound was stable for about $12 \mathrm{~h}$. With ivermectin, the compound that was exposed to light showed $95 \%$ of degradation in $5 \mathrm{~h}$ while, when flasks with protection from light were used, the compound was also stable for about $12 \mathrm{~h}$.

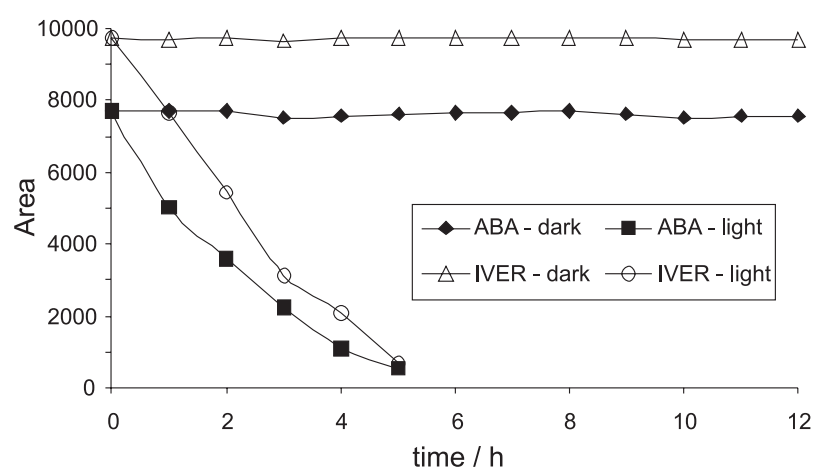

Figure 3. Stability of the analytical solutions of abamectin and ivermectin after derivatization with direct exhibition to light and protected from light, both at room temperature.

Another factor that influences the degradation of derivatized analytes is temperature. Thus, the influence of temperature was evaluated with analytical solutions of abamectin and ivermectin over the same concentration range. The flasks were protected from light, and submitted to three different temperatures: room, refrigerator and freezer, as shown in Figure 4.

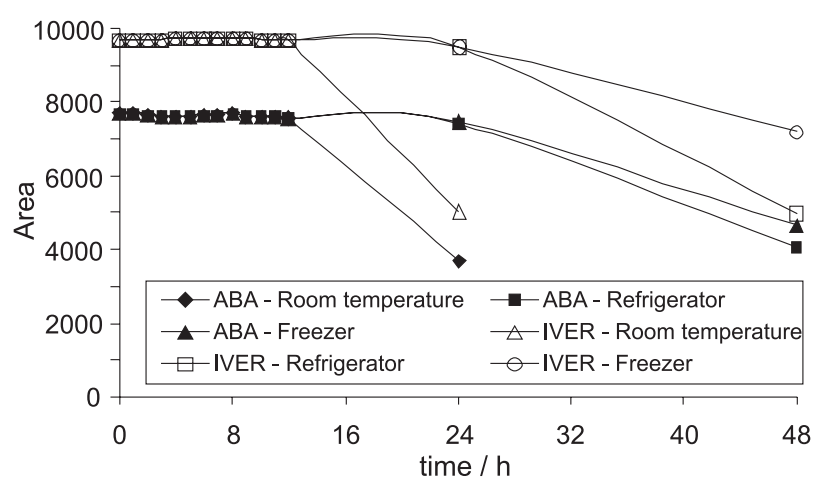

Figure 4. Stability of the analytical solutions of abamectin and ivermectin after derivatization under different temperature conditions. All flasks were protected from light.

It was observed that abamectin and ivermectin possess similar behaviors. At room temperature, little degradation was observed for up to $12 \mathrm{~h}$. However, after $24 \mathrm{~h}$ degradations of $48.5 \%$ for the abamectin derivative and $46.4 \%$ for that of ivermectin were seen. When the standard solution was maintained refrigerated or in a freezer, stability increased. No degradation was observed in $24 \mathrm{~h}$ for solutions maintained in the refrigerator, although after $48 \mathrm{~h}$ degradation reached $44.8 \%$ for the abamectin derivative and $46.0 \%$ for that of ivermectin. Similarly, when the solution was maintained in a freezer, degradation was not observed in $24 \mathrm{~h}$, however after $48 \mathrm{~h}$, the compounds showed $35.8 \%$ degradation for that of abamectin and $24.3 \%$ for that of ivermectin.

The derivatization step is simple and the reaction is instantaneous, but care should be taken to use flasks protected against light, keeping them in the refrigerator or freezer if the analysis times are over $12 \mathrm{~h}$ in order to prevent the degradation of the compounds

\section{Validation of the analytical method}

As no differences were observed in the standard solutions prepared in pure acetonitrile and in the blank milk extract, the analytical calibration curves were prepared in acetonitrile. These were found to be linear in the range of 1-10 $\mu \mathrm{g} \mathrm{L}-1$ for abamectin and 2-20 $\mu \mathrm{g} \mathrm{L} \mathrm{L}^{-1}$ for ivermectin; the representative linear regression equation was $\mathrm{y}=12846 \mathrm{x}-$ $5157\left(\mathrm{r}^{2}=0.9949\right)$ for abamectin and $\mathrm{y}=9326 \mathrm{x}-3965$ $\left(r^{2}=0.9995\right)$ for ivermectin.

The values of instrumental and method LOD and LOQ for abamectin and ivermectin are presented in Table 1. These limits permit the quantification of both pesticides in milk samples below the MRL values established by different legislations, showing excellent sensitivity of the developed method.

Table 1. Values of LOD and LOQ for the instrument and for the method

\begin{tabular}{lcccc}
\hline Compounds & $\begin{array}{c}\mathrm{LODi} / \\
\left(\mu \mathrm{g} \mathrm{L}^{-1}\right)\end{array}$ & $\begin{array}{c}\mathrm{LOQi} / \\
\left(\mu \mathrm{g} \mathrm{L}^{-1}\right)\end{array}$ & $\begin{array}{c}\mathrm{LODm} / \\
\left(\mu \mathrm{g} \mathrm{L}^{-1}\right)\end{array}$ & $\begin{array}{c}\mathrm{LOQm} / \\
\left(\mu \mathrm{g} \mathrm{L}^{-1}\right)\end{array}$ \\
\hline Abamectin & 0.6 & 1.0 & 0.10 & 0.18 \\
Ivermectin & 0.8 & 2.0 & 0.14 & 0.36 \\
\hline
\end{tabular}
$\mathrm{n}=3$.

Table 2 presents the recovery values for abamectin and ivermectin, which varied from 74.9 up to $101 \%$, values accepted for chromatographic methods applied to pesticide residue determinations (between 70 and $120 \%$ ), with RSD values below $15 \% .{ }^{29}$ The precision of the method, in terms of repeatability and intermediate precision, presented RSD values lower than $9.9 \%$, also considered acceptable.

The results show that the sample preparation and analysis were efficient and that the method can be used to determine abamectin and ivermectin in a complex samples such as milk. 
Table 2. Concentration levels of the fortified samples, recoveries and results of precision in terms of repeatability and of intermediate precision

\begin{tabular}{lccc}
\hline Compounds & $\begin{array}{c}\text { Fortify level/ } \\
\left(\mu \mathrm{g} \mathrm{L}^{-1}\right)\end{array}$ & Repeatability & $\begin{array}{c}\text { Intermediate } \\
\text { Precision }\end{array}$ \\
& 0.18 & $100.0 \pm 2.0$ & $101.0 \pm 4.8$ \\
Abamectin & 0.90 & $76.2 \pm 2.4$ & $73.4 \pm 5.2$ \\
& 1.80 & $85.1 \pm 5.1$ & $80.2 \pm 7.8$ \\
Ivermectin & 0.36 & $88.5 \pm 3.0$ & $84.0 \pm 9.9$ \\
& 1.80 & $74.9 \pm 4.8$ & $73.3 \pm 3.7$ \\
& 3.60 & $90.3 \pm 7.0$ & $88.0 \pm 5.1$ \\
\hline
\end{tabular}

$\mathrm{n}=3$.

The proposed method presented good performance when compared with others published works. Kijak, ${ }^{22}$ in an inter-laboratory study, determined ivermectin in bovine milk. The residues were isolated by a series of liquidliquid extraction steps using ethyl acetate, isooctane and ethanol. A partition with hexane was necessary to remove residual oil. The derivatization reagent employed was a solution of $N$-methylimidazole and acetic anhydride in $\mathrm{N}, \mathrm{N}$-dimethylformamide. The recoveries were from 59 to 95\% for a concentration of $1 \mathrm{mg} \mathrm{L}^{-1}$ and from 73 to $99 \%$ for a concentration of $4 \mathrm{mg} \mathrm{L}^{-1}$. Chiou et al. ${ }^{7}$ determined ivermectin in plasma and human milk using methanol for the extraction. The LOD was approximately $0.2 \mathrm{mg} \mathrm{L}^{-1}$ for plasma and $0.05 \mathrm{mg} \mathrm{L}^{-1}$ for milk. Recoveries were above $95 \%$. Schenck ${ }^{23}$ quantified ivermectin in bovine milk using matrix solid phase dispersion. The residues were eluted from the $\mathrm{C}_{18}$ /milk matrix with ethyl acetate. Average recoveries of ivermectin residues at concentrations of 1 to $8 \mu \mathrm{g} \mathrm{L}^{-1}$ were $97.7 \%$. Dusi et al..$^{24}$ determined ivermectin residues in milk for human consumption. The drug was extracted twice with acetonitrile and cleaned on a SPE $\mathrm{C}_{18}$. Fortifications in the concentration range from 2.8 to $55.6 \mu \mathrm{g} \mathrm{L}^{-1}$ recovered 70 to $80 \%$. Schenck and Lagman ${ }^{10}$ used the same procedure as Kijak ${ }^{22}$ to isolate abamectin, ivermectin, doramectin and moxidectin in samples of bovine milk. The recoveries were higher than $80 \%$ for fortification levels from 1 to $30 \mu \mathrm{g} \mathrm{L}^{-1}$. Dusi et al. ${ }^{25}$ developed an analytical method to determine ivermectin, abamectin, doramectin and moxidectin in milk for human consumption. Their LODs were below $1 \mu \mathrm{g} \mathrm{kg}^{-1}$ with recoveries higher than $70 \%$ for a concentration range from 5 to $60 \mu \mathrm{gg}^{-1}$.

\section{Application of the proposed method to milk samples}

The developed method was applied to determine abamectin and ivermectin in five raw milk samples and five commercial pasteurized whole milk type $\mathrm{C}$ samples obtained from local market. The samples were analized in triplicate. Results show that two samples of raw milk contained detectable residues. Abamectin was found in one raw milk samples at $4.9 \pm 0.3 \mu \mathrm{g} \mathrm{L}^{-1}$ and ivermectin was found in another raw milk sample at $1.3 \pm 0.1 \mu \mathrm{g} \mathrm{L} \mathrm{L}^{-1}$. No samples of commercial milk contained detectable concentrations of abamectin and ivermectin. All chromatograms were free from interferences. The concentration of abamectin found in raw milk was higher than the maximum residue limit established for milk by the Brazilian legislation.

\section{Conclusions}

The results reported in this paper allow us to conclude that the method is efficient and simple for the analysis of abamectin and ivermectin in milk. One of the advantages of the new extraction method is the use of only one solvent during the extraction, making it faster and producing less effluent. Another advantage of the new method is the preconcentration factor of circa 5 times, allowing quantification of low concentrations of analytes in milk samples. Quantification with a fluorescence detector is very selective and sensitive, allowing the determination of $1.0 \mu \mathrm{g} \mathrm{L}^{-1}$ of abamectin and $2.0 \mu \mathrm{g} \mathrm{L}{ }^{-1}$ of ivermectin, corresponding to the values of LOQ 0.18 and $0.36 \mu \mathrm{g} \mathrm{L}-1$ of the respective analytes in milk, which is considered a complex sample.

\section{Acknowledgments}

The authors are grateful to Conselho Nacional de Desenvolvimento Científico e Tecnológico (CNPq) and to Coordenação de Aperfeiçoamento de Pessoal de Nível Superior (CAPES) for financial support and fellowships.

\section{References}

1. Koesukwiwat, U.; Jayanta, S.; Leepipatpiboon, N.; J. Chromatogr. A 2007, 1140, 147.

2. Campbell, W. C.; New Zeal. Vet. J. 1981, 29, 174.

3. Vuik, J.; J. Chromatogr. 1991, 553, 299.

4. Alka, R. M.; Gopal, K. S.; Sandhu, P. K.; Vet. Parasitol. 2004, 121, 277.

5. Diserens, H.; Henzelin, M.; J. Chromatogr. A 1999, 833, 13.

6. Danaher, M.; Howells, L.; Crooks, S. R. H.; Flajs, V. C.; O’Keeffe, M.; J. Chromatogr. B 2006, 844, 175.

7. Chiou, R.; Stubbs, R. J.; Bayne, W. F.; J. Chromatogr. 1987, 416, 196.

8. Bassissi, M. F.; Alvinerie, M.; Lespine, A.; Comp. Biochem. Physiol., Part C: Toxicol. Pharmacol. 2004, 138, 437.

9. Imperiale, F.; Sallovitz, J.; Lifschitz, A.; Lanusse, C.; Food Addit. Contam., Part A 2002, 19, 810. 
10. Schenck, F. J.; Lagman, L. H.; J. AOAC Int. 1999, 75, 747.

11. http://www4.anvisa.gov.br/AGROSIA/asp/frm_dados_ ingrediente.asp? $\mathrm{iVarAux}=1 \& \operatorname{CodIng}=5$, accessed in June $14 / 2008$.

12. http://extranet.agricultura.gov.br/sislegis-consulta/servlet/ VisualizarAnexo?id=11053, accessed in June 14/2008.

13. http://www.ipfsaph.org/id/PESTMRL2137?language $=e n$, accessed in June 14/2008.

14. http://www.ipfsaph.org/id/VETMRL246?language=en, accessed in June 14/2008.

15. http://www.emea.eu.int/index/indexv1.htm, accessed in June $14 / 2008$.

16. Turnipseed, S. B.; Roybal, J. E.; Andersen, W. C.; Kuck, L. R.; Anal. Chim. Acta 2005, 529, 159.

17. Berendsen, B. J. A.; Mulder, P. P. J.; van Rhijn, H. J. A.; Anal. Chim. Acta 2007, 585, 126.

18. Bogialli, S.; Curini, R.; Corcia, A.; Laganà, A.; Stabile, A.; Sturchio, E.; J. Chromatogr. A 2006, 1102, 1.

19. Turnipseed, S. B.; Roybal, J. E.; Rupp, H. S.; Gonzáles, A. S.; Pfenning, A. P.; Hurlbut, J. A.; Rapid Commun. Mass Spectrom. 1999, 13, 493.
20. Howells, L.; Sauer, M. J.; Analyst 2001, 126, 155.

21. Valenzuela, A. I.; Redondo, M. J.; Pico, Y.; Font, G.; J. Chromatogr. A 2000, 871, 57.

22. Kijak, P. J.; J. AOAC Int. 1992, 75, 747.

23. Schenck, F. J.; J. Liq. Chromatogr. 1995, 18, 349.

24. Dusi, G.; Fierro, A.; Tognoli, N.; Ital. J. Food Sci. 1997, 9, 337.

25. Dusi, G.; Faggionato, E.; Bertocchi, L.; Facchetti, S.; Baiguera, M.; Industrie Alimentari 2001, XL, 11.

26. Payne, L. D.; Hicks, M. B.; Wehner, T. A.; J. Agric. Food Chem. 1995, 43, 1233.

27. ICH, International Conference on Harmonization, ICH Q2(R1), Guidance on Validation of Analytical Procedures: Text and Methodology, Geneva, 2005.

28. Pizzutti, I. R.; Kok, A.; Zanella, R.; Adaime, M. B.; Hiemstra, M.; Wickert, C.; Prestes, O. D.; J. Chromatogr. A 2007, 1142, 123.

29. Ribani, M.; Bottoli, C. B. G.; Collins, C. H.; Quim. Nova 2004, 27, 771 .

30. Juhler, R. K.; J. Chromatogr. A 1997, 786, 145.

Received: June 30, 2008

Web Release Date: April 30, 2009 